\title{
TEACHING PRACTICES: INTEGRATING POSITIVE THINKING IN PICTURE BOOK CREATION FOR ECONOMICALLY DISADVANTAGED CHILDREN
}

Chiu-Hua Huang

National Pingtung University, Taiwan E-mail: huangchiuhua19@gmail.com

Fin-Land Cheng National Pingtung University of Science and Technology, Taiwan

E-mail: chenfl@mail.npust.edu.tw

Ching-Yueh Teng The Affiliated Preschool of Fong-Ciou Elementary School, Taiwan E-mail: nataliedeng.nd@gmail.com

\begin{abstract}
The present study created picture books featuring elements of hope theory and conducted a practical teaching program to explore the application of hopeful thinking picture books for economically disadvantaged children, specifically, to understand the teachers' teaching practices of picture book creation. On the basis of hope theory, the current study employed economic disadvantage as the creative background for designing picture books that incorporate elements of hopeful thinking and developed a teaching plan based on the picture books. The results indicated that the picture books had a solid theoretical foundation of hope, and were relevant to preschool children's real experiences and development. Through teachers'storytelling and discussion of the story content, children could express ideas based on their own experiences, set specific goals, and devised feasible methods for handling adversity to achieve goals. Therefore, the picture books were considered suitable for classroom teaching. In addition, expert teachers serving as coaches conducted classroom observations and teaching evaluations to explore how effectively positive thinking was integrated into the picture books and teaching activities, and to assess the guidance of children in using positive thinking strategies during story discussion. Through professional assessment, feedback, and teacher self-reflection, hope theory can be effectively applied for picture book creation. The picture book The Piggy's Home created in this study can help teachers guide economically disadvantaged children in thinking positively, and teachers can refine the guidance process.
\end{abstract}

Keywords: case study, economically disadvantaged children, hope theory, picture books, preschool children

\section{Introduction}

Studies have conducted interventional educational programs for economically disadvantaged children (Blevins-Knabe, 2016; Fontenot et al., 2019; Gonzales-Ball, \& Bratton, 2019; Kluczniok, 2017; Lo et al., 2020; Shukri et al., 2019), but most have examined primarily cognitive achievements, such as those in mathematics and language (Gialamas et al., 2020; Maier et al., 2012; Pentimonti et al., 2017). Unfortunately, few studies have considered the mental status of economically disadvantaged children, and studies employing interventional 
Chiu-Hua HUANG, Fin-Land CHENG, Ching-Yueh TENG. Teaching practices: Integrating positive thinking in picture book creation for economically disadvantaged children

PROBLEMS

OF EDUCATION IN THE $21^{\text {st }}$ CENTURY Vol. 78, No. 6A, 2020

1082

education programs are particularly rare. However, the cognition and thinking habits of economically disadvantaged children can affect many aspects of their future development. Thus, researchers should also consider the negative thinking and mental status of such children as well as the subsequent adverse effects on future achievements (Bradshaw, 2002; Heberle et al., 2020).

Hope theory, developed by Snyder (2000), contends that hopeful thinking prevents problems, increases advantages, and integrates strategic pathways with goal-oriented thinking. Hope beliefs established before a problem occurs are reinforced in response to the challenges the problem poses. This concept is consistent with the notion of precaution long advocated by scholars (Snyder et al., 2003); that is, early educational intervention to promote hopeful thinking prevents future problems.

Teaching materials often critically influence the success of educational interventions (Penuel et al., 2012), quality of the interactions between teachers and students, and effectiveness of children's early learning (Bayhan et al., 2002). Some researchers have attempted to improve the abilities of economically disadvantaged children through interventions that involve designing various curriculum materials (Chatterji, 2006; Penuel et al., 2012). Picture books have been demonstrated to effectively cultivate children's thinking (Higham et al., 2010) and improve their mental and emotional states (Farkas et al., 2018; Farkas et al., 2020). Phillips and Sturm (2013) analyzed the illustrations and texts of 13 picture books for young children; they discovered that a well-developed picture book can help teachers understand children's learning adaptation and satisfaction. Therefore, picture books have become teachers' preferred materials for educational interventions, especially those for first-grade or preschool children (Tompkins et al., 2018). It is clear that a picture book with a theoretical basis is a good medium for of educational interventions of young children.

This case study explored the creation of picture books featuring elements of hope theory and conducted a practical teaching program to explore the application of hopeful thinking picture books. In contrast to previous research, the current study was not limited to ready-made picture books; instead, the positive thinking element of hope theory was incorporated in the creation of a picture book with the aim of altering the negative thinking of children living in a culture of poverty. The researchers encouraged teachers to reflect on and adjust their teaching practices with the created picture books and to evaluate whether the books effectively presented hopeful thinking. In particular, the research questions were as follows:

1. How effectively were hope theory and the characteristics of hopeful thinking integrated into picture book creation?

2. How can picture books emphasizing positive thinking be used in teaching activities for economically disadvantaged children, and how can children be provided the experience of positive thinking?

\section{Literature Review}

\section{Crucial Early Interventions for Economically Disadvantaged Children}

Children living in a culture of poverty experience negative long-term consequences, such as poor academic performance, that affect both individuals' lives (Alexander et al., 1997; Duncan \& Magnuson, 2005; Esping-Andersen \& Sarasa, 2002; Hauser-Cram et al., 2006; Parcel \& Dufur, 2001). In addition to lacking material resources, economically disadvantaged people experience problems related to social networks and have limited educational and employment opportunities (Vågerö \& Illsley, 1995), resulting in social exclusion and perpetuating an intergenerational cycle of poverty (McLoyd, 1998). Chafel and Neitzel (2005) discovered that 8-year-old children perceived poverty to be alterable. However, as they age, children 
become more accepting of their economically disadvantaged social condition, tend to attribute Vol. 78 , No. $6 \mathrm{~A}, 2020$ poverty more to personal factors, and begin to consider it inevitable (Chafel \& Neitzel, 2005; Leahy, 1990). Therefore, from the perspective of prevention, positive development and early intervention should be implemented to overcome intergenerational cycles of poverty.

\section{Positive Psychology: Hope}

Hope theory is a major theory within positive psychology proposed by Snyder (1994). According to hope theory, hope involves setting goals to solve problems; pathways, or the various methods employed to realize goals; and agency, or the drive to achieve goals through self-efficacy. The clearer, important, and feasible an individual's goal, the more hopeful is the individual. Pathways allow individuals to develop multiple paths to achieve goals. Agency refers to an individual's willpower in the process of achieving goals. Hope theory enables the definition of clear and meaningful goals and the development of strong motivations and strategies for pursuing personal goals (Snyder et al., 2006). Hope is a positive and reasonable expectation of the future, and such positive thinking not only motivates individuals to devote effort toward overcoming obstacles in their environments but also improves their coping abilities (Snyder et al., 2006). Snyder (2000) argued that cultivating hope prevents problems and enhances personal advantages; therefore, positive cognition, thinking, and belief should be established among economically disadvantaged children to help prevent and overcome adversity. Furthermore, Snyder et al. (1997) stated that hope develops through observation, imitation, and internalization in early childhood. Children observe and imitate the attitudes, behaviors, and beliefs of important others; they subsequently identify with and internalize those attitudes, behaviors, and beliefs. According to Snyder (2005), applying hope theory is crucial in teaching interventions. Through hope-based teaching interventions, children can learn to set clear goals, find ways to overcome obstacles, and remain motivated.

Ciarrochi et al. (2007) conducted a longitudinal study and discovered that hope was the variable most predictive of positive emotions and academic achievement. Waters (2011) reviewed 12 school-based positive psychology interventions designed to foster student wellbeing and academic performance. The author indicated that increasing the hope of economically disadvantaged children is a crucial objective of early educational intervention programs.

\section{Picture Book-Based Interventions for Economically Disadvantaged Children}

Recent longitudinal studies have indicated that early educational interventions benefit economically disadvantaged children's development of intellectual and linguistic skills (Chatterji, 2006; Penuel et al., 2012) and improves their motivation, confidence, and ability to adapt at school (Reynolds et al., 2002). Curriculum materials crucially influence children's early learning and children were demonstrated to achieve superior learning outcomes when teachers selected appropriate materials (Bayhan et al., 2002). Graham (1990) discovered picture books to be the optimal teaching materials for inspiring young children's thinking. Educators rely on picture books as curriculum materials, and they are often used during the preschool day (Leal, 1993; Martucci, 2016). Numerous studies have demonstrated that sharing picture books is associated with increased mental- and emotional-state talk and children's socioemotional competence (Bergman Deitcher et al., 2020; Kristen et al., 2016; Tompkins et al., 2018). Consequently, picture books have become the preferred instruction materials of scholars investigating issues related to the psychology of economically disadvantaged children. However, previous studies (e.g., Higham et al., 2010) employing picture books as curriculum material have used primarily ready-made, published books. Thus, such studies are somewhat limited and may be unable to fully integrate theoretical elements into a shared book reading 
Chiu-Hua HUANG, Fin-Land CHENG, Ching-Yueh TENG. Teaching practices: Integrating positive thinking in picture book creation for economically disadvantaged children

PROBLEMS

OF EDUCATION

IN THE $21^{\text {st }}$ CENTURY Vol. 78 , No. 6A, 2020

1084

intervention. In addition, the context of ready-made storybooks may differ from children's life experiences and mental states, thereby limiting the effectiveness of shared storybook reading.

Storytelling for the Home Enrichment of Language and Literacy Skills (SHELLS) interventions employs a narrative of daily family events as the content for developing a book, which families can keep and continue to use. The basic steps of the book creation process are encouraging the family to generate ideas for book topics through parent-child conversation, illustrating the story, writing captions that incorporate words or sentences from the parent-child narrative, organizing and creating the physical book, and observing the parent and child using the book. Boyce et al. (2010) used SHELLS activities developed specifically for low-income Spanish-speaking families to overcome the limitation of using only existing teaching materials. Their results revealed that SHELLS increased children's use of language in narratives and promoted parents' support of their children's language and literacy skills. Therefore, the content of a picture book or other teaching materials can considerably influence teaching interventions.

Most relevant studies have focused on improving economically disadvantaged children's cognitive and linguistic achievements, but studies involving positive psychology are rare. Tompkins (2015) indicated that using storybooks in conjunction with discussion of characters' mental states helped economically disadvantaged children to develop false belief understanding. Therefore, this study avoided the traditional limitation of using pre-existing teaching materials by creating a unique picture book for teaching economically disadvantaged children that incorporated the concept of hopeful thinking.

\section{Role of Coaches}

The primary limitation to preschools' effectiveness is an inability to effectively integrate new curriculum materials with the skills of current teachers (Davidson et al., 2009). Therefore, scholars have emphasized the use of professional support systems to facilitate the integration of effective materials and teaching skills (Klute, 2012; Penuel et al., 2012). Coaches are crucial for improving teaching techniques (Klute, 2012). When teachers introduce new material into their curricula, coaches employ professional development models to assess teaching and provide feedback, enabling teachers to optimize their teaching effectiveness (Landry et al., 2009). In addition to the appropriate picture book, the appropriate teaching strategy is crucial in teaching interventions for economically disadvantaged children. The assistance and feedback of coaches are informative and indispensable resources for teachers using picture books to guide young children in the development of hopeful thinking strategies (Chafel \& Neitzel, 2005). By having coaches conduct nonparticipatory observation and teaching evaluation, researchers could adjust the integration of positive thinking into the picture books as well as their application in teaching.

The coaches in this study were preschool teachers at the participating in this study school. They were qualified preschool teachers with more than 3 years of teaching experience and master's degrees in preschool education. They supervised and assessed the teaching process and provided suggestions and perspectives to help the teachers improve their skills and adjust their integration of hope into the picture book.

\section{Research Methodology}

\section{General Background}

This case study provided an in-depth description of the integration of positive thinking in the creation of a picture book for economically disadvantaged children and teaching practice. Two criteria were used in the study: (1) implemented in a natural context of preschool; (2) the study is mainly exploratory in nature. 
This research was conducted in a preschool located in a village in Neipu Township, Pingtung County in Taiwan. According to statistics for 2020 provided by the Ministry of Health and Welfare, Pingtung County has the second highest proportion of economically disadvantaged households in Taiwan (Ministry of Health and Welfare, 2020). Among the 33 townships in Pingtung Counting, Neipu Township has the second most households living in poverty, accounting for $7.65 \%$ of such households in the county (Ministry of Health and Welfare, 2020). Therefore, this study adopted Pingtung as the research background and incorporated two elements: positive thinking and poverty into picture book creation. And teachers use picture books to actually teach in local preschool.

\section{Research Participants}

The research team comprised two teachers, three coaches, and one professional advisor, and the research participants were 18 preschool children, comprising 8 girls and 10 boys. The study was conducted after school at $4 \mathrm{pm}$. Parents decided whether their children participated. The storytelling activities were mainly based on the picture book story, The Piggy's Home, which was developed in this study. No fees were charged for participation.

\section{Data Collection}

Consistent with case study methodology, the data collection relies on multiple data sources to converge in order to provide a means to triangulate findings (Yin, 2014), including audiotaped interviews with coaches and teachers, videotaped classroom observations, and teaching technique checklist.

Observations and interviews:

A familiarization period was arranged before the coaches conducted nonparticipatory observation and teaching evaluation, the purpose of which was to allow the children to become used to the camera and the research team. Following the observations, the professional advisor interviewed the two teaching teachers from the participating classes and three coaches, developing a semi-structured interview protocol on insights gained from the observations and document analysis to encourage the teachers to report on children's response and their teaching situation.

Teaching technique checklist:

Based on the teaching technique checklists that the coaches completed during observation, the fit between the hope-based picture books and the teaching applications was analyzed. The checklist items were used to assess the five following dimensions:

(1) Activity procedure: The teachers' level of coordination during the activities as well as the appropriateness of the teaching process.

(2) Instructional techniques: The questioning techniques employed by teachers during the storytelling activities such as discussing the facial expressions of the story characters as well as guiding the children to empathize with the protagonist of the story and propose problem-solving goals, strategies, and ways to maintain willpower.

(3) Children's responses: The interactions between the children and teachers during 
Chiu-Hua HUANG, Fin-Land CHENG, Ching-Yueh TENG. Teaching practices: Integrating positive thinking in picture book creation for economically disadvantaged children

PROBLEMS

OF EDUCATION

IN THE $21^{\text {st }}$ CENTURY Vol. 78 , No. $6 \mathrm{~A}, 2020$

1086

the storytelling activities, such as the children's willingness to actively express their ideas with encouragement from their teachers.

(4) Picture book creation: The pictures and characters in the picture book, which provided positive thinking, and the background of the story, which was similar to the life experiences of the children.

(5) Commercial publishing: Appropriateness of the book for commercial publication and teaching application.

\section{Creation of the Hope-Integrated Picture Book}

Teachers may use wordless books to provide children the opportunity to practice thinking, and asking children to describe the feelings and motives of characters in picture books promotes teaching effectiveness (Jalongo et al., 2002). Therefore, we created the wordless picture book The Piggy's Home using poverty as the theme to communicate a positive and hopeful perspective toward poverty and encourage young children to develop a positive attitude.

Because this was a wordless picture book, the teachers first designed a short story to introduce the background. This story described the protagonist, Little Piggy, who lived in an economically disadvantaged environment and faced many problems. Then, in accordance with hope theory, the teachers encouraged and guided the children to look at the pictures, tell stories, and help Little Piggy to propose methods for problem solving, such as setting goals, strategies for completing goals, and approaches to inspire hope and maintain willpower. The application of hope theory in picture book teaching is explained as follows:

Goals: The children first discussed, listed, and prioritized the goals of the protagonist. The teacher assisted the children in focusing these goals. After the goals were established, the teacher provided several methods to help the protagonist remain focused on the goal (e.g., write down the goal on a card and post it on the wall).

Pathway thoughts: The teacher asked the children to suggest several possible ways that the protagonist could achieve the established goals. The teacher could invite children to demonstrate these methods through speaking and acting.

Agency thoughts: The teacher provided status questions. For example, when Little Piggy began to doubt himself, the teacher invited the children to discuss Little Piggy's possible feelings and provide positive self-talk, such as "I want to change" or "I can choose," to help increase Little Piggy's self-efficacy.

\section{Producing Creations}

\section{Preparing to create the picture book}

Researchers collected and read picture books and books on the theme of poverty.

2. $\quad$ Selecting creative material for the picture book

Acrylic paint was used for the initial illustration because (a) it has a smooth and bright finish and a natural and even effect; (b) it ensures that the saturation is constant and the effects are consistent; (c) it possesses the characteristics of both watercolor and oil paints as well as water resistance; (d) it tolerates a high degree of color overlay, enabling errors to be corrected during the illustration process.

3. Picture book design

Production methods: Muppets-style puppets of Little Piggy were hand painted and sewn to present the story flexibly.

4. Character design

The story characters were primarily animals such as Little Piggy, making the story enjoyable for children. 
Chiu-Hua HUANG, Fin-Land CHENG, Ching-Yueh TENG. Teaching practices: Integrating positive thinking in picture book creation for economically disadvantaged children

5. Level of appropriateness

IN THE $21^{\text {st }}$ CENTURY

Vol. 78 , No. 6A, 2020

Creating books with only pictures facilitate creativity and imagination and are suitable for children of various ages.

\section{Procedures}

The procedures of this study comprised the following stages: planning, implementing and observation, reflection and revision, and data analysis and reporting (Figure 1).

\section{Figure 1}

\section{The Present Research Procedure}

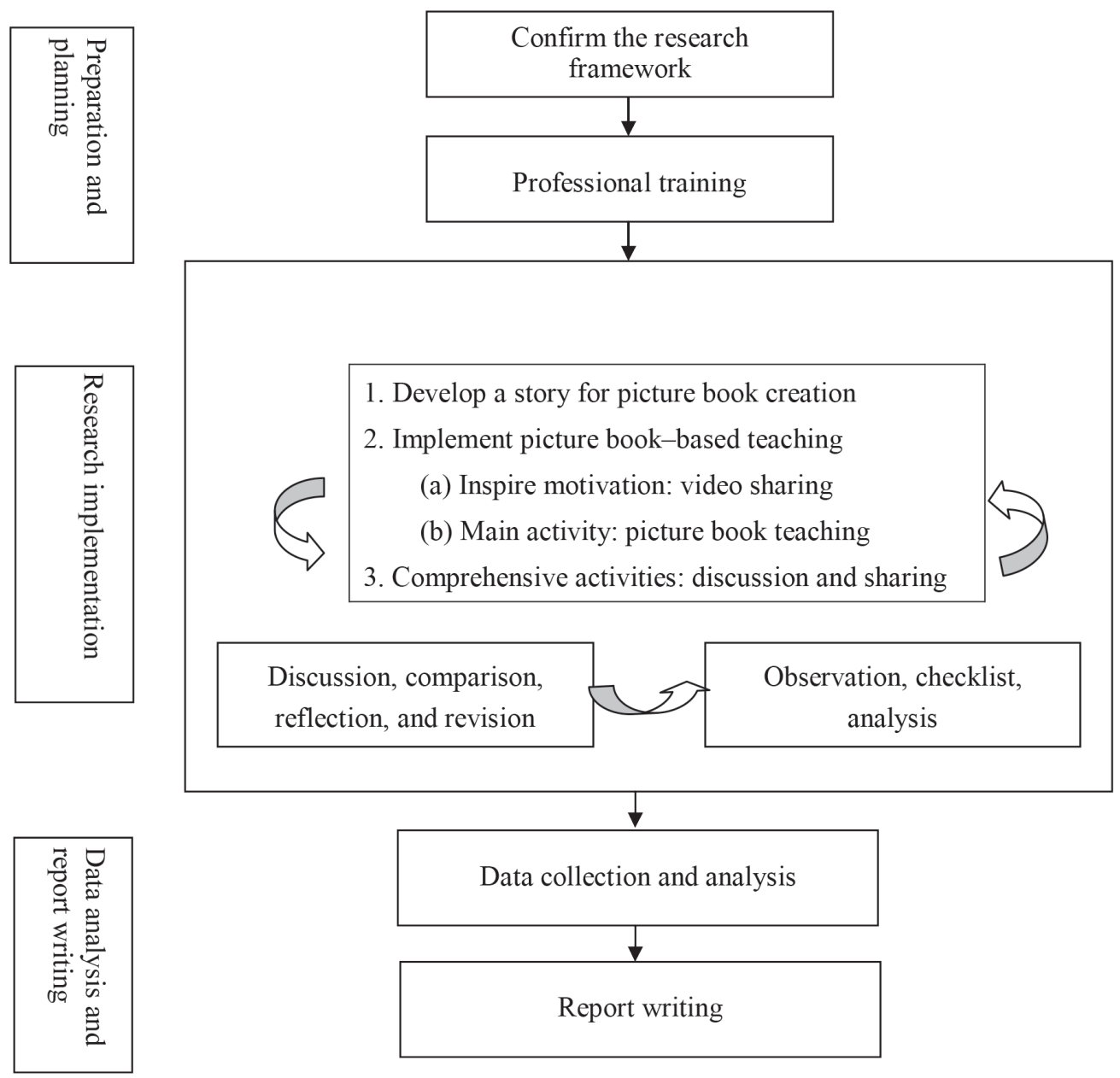

1. Preparation and planning stages

(1) Confirming the theme and theoretical basis

Elements of hope theory were used as the theme for the picture book design, and characteristics specific to the culture of poverty in Pingtung County, Taiwan, were used to plan the characters' backstories. Intervention effects can be optimized by referencing children's real experiences (Boyce et al., 2010). To optimize the effectiveness of teaching with the created picture books, we designed teaching plans for storytelling activities that incorporated hope and implemented these activities in educational settings. 
Chiu-Hua HUANG, Fin-Land CHENG, Ching-Yueh TENG. Teaching practices: Integrating positive thinking in picture book creation for economically disadvantaged children

PROBLEMS

OF EDUCATION

IN THE $21^{\text {st }}$ CENTURY

Vol. 78, No. 6A, 2020

1088

(2) Professional training

This study was conducted by research team, who had received theoretical and practical training. During each step of the creation process, the research team confirmed that elements of hope theory had been appropriately incorporated into the picture book. This ensured that hope theory was fully integrated and practically applied.

2. Research implementation stages

(1) Practice and observation

Before conducting this study, the teachers contacted the participating preschool to confirm the classes that would be involved in this study and coordinate the dates and times for the teaching activities. The teachers arranged their schedules and work content on the basis of the teaching times, including the allocation of teachers, teaching assistants, equipment, and research tools. Each teaching session lasted up to $40 \mathrm{~min}$, and the entire process was recorded on video. The coaches were instructed to observe the teaching process and complete the checklist.

(2) Reflection and revision

As nonparticipants, the coaches observed the teachers' teaching techniques and the children's responses and completed the teaching technique checklist. The teachers and the advisor discussed and modified the teaching techniques to be employed in subsequent lessons on the basis of the coaches' evaluations and the children's responses during classes, achieving a cyclical revision process. Teachers could reflect on the intervention and make adjustments if difficulties occurred. Therefore, we could revise and adjust the teaching methods throughout the course of research.

3. Data analysis and report writing stages

Before discussing the data, analysis and report writing procedures with coaches, the teachers and advisor conducted a comprehensive review and assessment of the data obtained during the teaching process. The data analysis process comprised two stages. First, the coaches evaluated the teaching technique checklist, with a response of excellent worth 5 points and poor worth 1 point. A higher score indicated superior performance in that dimension. The professional advisor analyzed the coaches' feedback to help the teachers to improve their strategies for integrating the picture book into teaching. Second, the texts of the transcribed teaching video recordings, teaching journals, and teachers' self-reflections were analyzed.

\section{Research Results}

\section{Coaches' Professional Evaluations}

\section{Analysis of coaches' checklist results}

Table 1 presents the descriptive statistics of the coaches' evaluations of the teaching techniques employed to teach the picture book The Piggy's Home. The overall mean score for all five dimensions was 4.76, with the instruction techniques dimension receiving the lowest mean score of 3.50, indicating room for improvement. By contrast, the picture book creation dimension achieved the highest mean of 4.93 . 
Chiu-Hua HUANG, Fin-Land CHENG, Ching-Yueh TENG. Teaching practices: Integrating positive thinking in picture book creation for economically disadvantaged children

Table 1

Descriptive Statistics of the Checklist Evaluations of Techniques Employed to Teach "The 1089 Piggy's Home"

\begin{tabular}{lllll}
\hline Dimension & $\boldsymbol{M}$ & $\boldsymbol{S D}$ & Maximum & Minimum \\
\hline Activity procedure & 4.93 & 0.15 & 5.00 & 4.67 \\
Instruction techniques & 4.50 & 0.64 & 5.00 & 3.50 \\
Children's responses & 4.67 & 0.47 & 5.00 & 4.00 \\
Picture book creation & 4.90 & 0.15 & 5.00 & 4.67 \\
Commercial publishing & 4.80 & 0.45 & 5.00 & 4.00 \\
Overall & 4.76 & 0.20 & 4.94 & 4.47 \\
\hline
\end{tabular}

\section{Coaches feedback and recommendations}

The coaches recommended that the teachers improve their discussion skills and that the process be more closely related to the connotations of hope theory. For example, in the goal setting stage, if the range of goals proposed by the children was too large, the teachers tried to guide the children to focus on more specific goals. The coaches suggested that the teachers help the children divide a large goal into several sub-goals to render them more concrete and feasible. In addition, the picture book creation dimension was judged to be excellent. Examples of the coaches' feedback are provided below.

Coach A: "The themes were diverse and could stimulate significant interest and motivation to participate among the children. Additionally, the teachers' body language was lively. Using Muppets-style puppets and the storyline, the teachers vividly presented the story in the picture book. Judging by the children's responses, I believe that participation in teaching activities can lead to positive and optimistic thinking. But during the process of story discussion, it is recommended that the teacher write down all the children's ideas, a bit like an experience chart, and then discuss with children how to make the ideas concrete."

Coach B: "The story in the picture book was closely linked to the theme of hope. The teacher orally expressed the background of this story, which aroused the children's interest. After explaining the story background and the difficulties faced by Little Piggy, the teacher encouraged the children to think about the future development of the story as well as to set goals and propose strategies. Children have the opportunity to experience and simulate how to find a solution to the breakthrough dilemma. The teachers used diverse facial expressions and gestures to present the story, effectively capturing the attention of all the children."

Coach C: "It is a great picture book. The story is presented using large pictures, and the characters and the plot are closely related to young children's life experiences. However, suggest that when the teacher discusses with the child, if the child's ideas are too abstract, the teacher can give one or two examples to demonstrate."

\section{Analysis of Hope-Based Picture Book and Reflections on Teaching Application}

1. Effectiveness of incorporating hope theory and the culture of poverty into the picture book creation

In this study, hope theory and the culture of poverty were incorporated into a picture book "Piggy's Home" to increase the hopefulness, positivity, and concreteness of young children's thought by teaching practice. During the creation process, the advisor and teachers 
Chiu-Hua HUANG, Fin-Land CHENG, Ching-Yueh TENG. Teaching practices: Integrating positive thinking in picture book creation for economically disadvantaged children

PROBLEMS

OF EDUCATION

IN THE $21^{\text {st }}$ CENTURY Vol. 78, No. 6A, 2020

1090

incorporated elements of hope theory into the plot, considered the characteristics and stages of young children's cognitive development, and ensured that the story was related to the life experiences of the participating children. The results of this study demonstrated that a research team with expertise in childcare, education, and art can develop a theoretically sound picture book based on hope theory and the culture of poverty and effectively employ it in practical teaching.

2. Hope-based picture books are effective teaching materials for positive thinking teaching

The hope-based picture book developed in this study was incorporated into teaching design. In addition to establishing a corresponding teaching plan, we used the coaches' professional evaluations to increase teaching effectiveness. The clear theme and rich content of the picture book attracted considerable interest from the children and enabled the teachers to guide the children toward positive thinking. According to the analysis of videotaped classroom observations revealed that the teacher 1 believes that the hope-based picture books can be a teaching material for her to guide children to positive-think forward, and it can also effectively arouse children's active response. As she explained:

Teacher 1: "Today I discussed with the children how to solve the problem that Piggy does not have enough money to hire workers to repair the leaking house. The usually quiet child Mindy raised her hand and said: Piggy can start planning to save money and if you have money, you can ask workers to repair it. Allen said: But it takes a long time to save money, and the house will flood. Mindy also said: You still have to plan to save money because you will need to use it later...... At this time, I continued to respond and ask questions: Planning to save money is a good way, so if we don't have enough money to ask someone to repair it, how can Piggy help himself? Mindy said: Piggy can ask neighbors for help or learn to repair it by himself, just like my grandpa repairs a bicycle by himself, it is free." Ann said: You can also take a bucket to catch water.

3. Teachers'self-reflection:

During the teaching activities, the research team conducted several reviews and discussions and maintained detailed records as a reference for improving subsequent teaching. Examples of the teachers' reflections are provided as follows:

Teacher 1: "The background of the story closely resembles the children's real-life experiences. The children can put forward their own ideas during the discussion process and occasionally use their own experience as examples. However, I hope to enable children to set specific goals and keep expectations of achieving the goal. Sometimes I worry that the goals put forward by children are too abstract, and I don't know how to continue the discussion. The application of teaching skills seems not so ideal. I think the application of theory must be strengthened." "The story teaching was conducted smoothly. However, the teachers did not accurately monitor the time when executing the development activity 'hope balloon' and the comprehension activity 'sharing' from the teaching plan. Consequently, the children did not have sufficient time to share their ideas, although they all actively participated."

Teacher 2: "The story of the picture book is closely linked to young children's life experience and using animals as the characters and Muppets-style puppets to present the story successfully captured the interest of the young children. In addition, during the teaching process, children used their own experience to describe the emotions of the protagonist of the story. This is a good start. They already are aware of the existence of feelings and accept the occurrence of negative emotions. Unfortunately, I seldom discuss with young children how to regulate emotions so that emotions will not affect the achievement of goals, which is the maintenance of willpower. Next time, I think the teaching should incorporate this part." 


\section{Discussion}

The aim of the present study was to create a picture book featuring the positive thinking elements of hope theory, and to implement a practical teaching program exploring the application of the picture book. This design overcame the limitations of previous studies, which relied on commercially available picture books (e.g., Higham et al., 2010; Martucci, 2016). The teachers deliberated regarding how to effectively incorporate the essential elements of hope theory into the picture book, and they discussed literature collection, clarified the concepts of hope theory, and prepared teaching plans. Finally, the picture book was successfully created. In addition, after teaching with the picture book and discussing with the coaches, the teachers expressed clear awareness of aspects of the teaching process that can be improved, such as guiding children through teaching strategies to discuss the core concepts of hope theory. For example, in the agency thought stage, when encountering setbacks or difficulties, individuals should set clear goals (Snyder et al., 2006), but the process of achieving those goals inevitably includes negative emotions, setbacks, and challenges. Therefore, teachers should discuss with children how to maintain individual willpower in the process of achieving goals (Snyder, 2000). This is also the core concept of hope theory. In addition, teacher reflections revealed that even positive thinking can be used to guide classroom discussions through picture books, but this notion is relatively unfamiliar to teachers. Therefore, discussing it with coaches will help with teaching implementation.

Picture books are a commonly used teaching aid among preschool teachers. However, related research has mainly focused on ready-made picture books. Therefore, teaching goals must consider the context and scope of ready-made textbooks, resulting in limited teaching effects. In addition, the stories of ready-made textbooks may be irrelevant to children. The real-life experiences of the children may differ, or topics may be beyond the scope of the children's understanding, especially storybooks that cultivate children's mental health or positive thinking. Boyce et al. (2010) used narratives of daily family events in low-income Spanish families as the content of their books and improved children's literacy skills by using these books. Unfortunately, their research did not explore issues related to children's positive thinking and social abilities. Previous studies have shown that picture books are an effective medium for improving children's positive thinking and emotions and can promote positive social abilities (Bergman Deitcher et al., 2020; Kristen et al., 2016; Tompkins et al., 2018). The current study provides an example of the creation of a picture book incorporating the positive thinking element of hope theory. It also explores the use of picture books for teaching positive thinking in young children.

\section{Conclusions and Implications}

Picture books are a useful teaching medium and are familiar to preschool teachers. The creation of a picture book with a clear theoretical framework offers the opportunity to significantly enhance its teaching effects. Moreover, this is a valuable opportunity for teachers to develop professionally. Several conclusions were drawn from the results of this study. First, a picture book based on positive thinking theory can be effectively applied in teaching. Second, teachers can achieve teaching objectives more systematically under the guidance of a clearly theoretically based picture book. Third, through the feedback of coaches, teachers have the opportunity to improve their teaching strategies, such as using experience charts in story discussions and expressing abstract thinking through body language. Fourth, when the background of the story is similar to children's real-life experience, and children are encouraged to extract their own experience in the discussion, they will be more active in the discussion. Moreover, children can propose possible problem-solving strategies and predict various outcomes. 
Chiu-Hua HUANG, Fin-Land CHENG, Ching-Yueh TENG. Teaching practices: Integrating positive thinking in picture book creation for economically disadvantaged children

PROBLEMS

OF EDUCATION IN THE $21^{\text {st }}$ CENTURY Vol. 78 , No. 6A, 2020

1092

Future studies can employ group teaching to offer children more opportunities to express their ideas about the stories presented by picture books. Such expression would enable teachers to direct young children away from their negative manners of thinking and toward positive thinking strategies, thereby achieving superior teaching outcomes. In addition, teachers can extend single-session activities into a series of class-specific activities to conduct longitudinal interventions. Because picture books such as the one in this study are wordless, teachers can involve young children in plot creation. During this process, teachers can thoroughly understand children's perceptions and feelings regarding poverty. Furthermore, teachers can use the discussion process to instruct young children to employ positive thinking in the creation of stories and encourage them to learn to solve problems actively. More importantly, this process minimizes teacher dominance of discussion, thereby providing education based on children's perspectives. Future studies can encourage children to become storytellers, and the leader of the storytelling activity can create additional opportunities for children to actively absorb and practice hopeful thinking.

\section{References}

Alexander, K. L., Entwisle, D. R., \& Horsey, C. S. (1997). From first grade forward: Early foundations of high school dropout. Sociology of Education, 70(2), 87-107. https://doi:10.2307/2673158

Bayhan, P., Olgun, P., \& Yelland, N. J. (2002). A study of pre-school teachers' thoughts about computer-assisted instruction. Contemporary Issues in Early Childhood, 3(2), 298-303. https://doi.org/10.2304/ciec.2002.3.2.11

Bergman Deitcher, D., Aram, D., Khalaily-Shahadi, M., \& Dwairy, M. (2020). Promoting preschoolers' mental-emotional conceptualization and social understanding: A shared book-reading study. Early Education and Development, 1-15. https://doi.org/10.1080/10409289.2020.1772662

Blevins-Knabe, B. (2016). Early mathematical development: How the home environment matters. In Blevins-Knabe B., Berghout Austin A. M. (Eds.), Early childhood mathematical skill development in the home environment (pp. 7-28). Springer.

Boyce, L. K., Innocenti, M. S., Roggman, L. A., Norman, V. K. J., \& Ortiz, E. (2010). Telling stories and making books: Evidence for an intervention to help parents in migrant head start families support their children's language and literacy. Early Education \& Development, 21(3), 343-371. https://doi.org/10.1080/10409281003631142

Bradshaw, J. (2002). Child poverty and child outcomes. Children \& Society, 16(2), 131-140. https://doi.org/10.1002/chi.707

Chafel, J. A., \& Neitzel, C. (2005). Young children's ideas about the nature, causes, justification, and alleviation of poverty. Early Childhood Research Quarterly, 20(4), 433-450. https://doi.org/10.1016/j.ecresq.2005.10.004

Chatterji, M. (2006). Reading achievement gaps, correlates, and moderators of early reading achievement: Evidence from the Early Childhood Longitudinal Study (ECLS) kindergarten to first grade sample. Journal of Educational Psychology, 98(2), 489-507. https://doi.org/10.1037/0022-0663.98.3.489

Ciarrochi, J., Heaven, P. C. L., \& Davies, F. (2007). The impact of hope, self-esteem, and attributional style on adolescents' school grades and emotional well-being: A longitudinal study. Journal of Research in Personality, 41(6), 1161-1178. https://doi.org/10.1016/j.jrp.2007.02.001

Davidson, M. R., Fields, M. K., \& Yang, J. (2009). A randomized trial study of a preschool literacy curriculum: The importance of implementation. Journal of Research on Educational Effectiveness, 2(3), 177-208. https://doi.org/10.1080/19345740902770028

Duncan, G. J., \& Magnuson, K. A. (2005). Can family socioeconomic resources account for racial and ethnic test score gaps? The Future of Children, 15(1), 35-54. http://www.jstor.org/stable/1602661

Esping-Andersen, G., \& Sarasa, S. (2002). The generational conflict reconsidered. Journal of European Social Policy, 12(1), 5-21. https://doi.org/10.1177/0952872002012001560

Farkas, C., Del Real, M. T., Strasser, K., Álvarez, C., Santelices, M. P., \& Sieverson, C. (2018). Maternal mental state language during storytelling versus free-play contexts and its relation to child language and socioemotional outcomes at 12 and 30 months of age. Cognitive Development, 47, 181-197. https://doi.org/10.1016/j.cogdev.2018.06 
Chiu-Hua HUANG, Fin-Land CHENG, Ching-Yueh TENG. Teaching practices: Integrating positive thinking in picture book creation for economically disadvantaged children

Farkas, C., Santelices, M. P., Vallotton, C. D., Brophy-Herb, H. E., Iglesias, M., Sieverson, C., Cuellar, M. D. P., \& Álvarez, C. (2020). Children's storybooks as a source of mental state references: Comparison between books from Chile, Colombia, Scotland and USA. Cognitive Development, 53, 1-16. https://doi.org/10.1016/j.cogdev.2019.100845

Fontenot, B., Uwayo, M., Avendano, S. M., \& Ross, D. (2019). A descriptive analysis of applied behavior analysis research with economically disadvantaged children. Behav Analysis Practice, 12, $782-$ 794. https://doi.org/10.1007/s40617-019-00389-8

Gialamas, A., Haag, D. G., Mittinty, M. N., \& Lynch, J. W. (2020). Educational activities on language and behavioural outcomes at school entry are more important for socioeconomically disadvantaged children: a prospective observational study of Australian children. Journal Epidemiol Community Health, 74, 770-777. http://dx.doi.org/10.1136/jech-2020-213856

Gonzales-Ball, T. L., \& Bratton, S. C. (2019). Child-teacher relationship training as a Head Start early mental health intervention for children exhibiting disruptive behavior. International Journal of Play Therapy, 28(1), 44-56. https://doi.org/10.1037/pla0000081

Graham, J. (1990). Pictures on the page. National Associal for the teaching of English.

Hauser-Cram, P.,Warfield, M. E., Stadler, J., \& Sirin, S. R. (2006). School environments and the diverging pathways of students living in poverty. In A. C. Huston \& M. N. Ripke (Eds.), Developmental contexts in middle childhood (pp. 198-216). Cambridge University Press.

Heberle, A. E., Carter, A. S., \& Dubow, E. F. (2020). Is poverty on young minds? Stereotype endorsement, disadvantage awareness, and social-emotional challenges in socioeconomically disadvantaged children. Developmental Psychology, 56(2), 336-349. https://doi.org/10.1037/dev0000883

Higham, S., Tönsing, K. M., \& Alant, E. (2010). Teachers' interactions during storybook reading: A rural African perspective. Early Education \& Development, 21(3), 392-411. https://doi.org/10.1080/10409281003668052

Jalongo, M. R., Dragich, D., Conrad, N. K., \& Zhang, A. (2002). Using wordless picture books to support emergent literacy. Early Childhood Education Journal, 29, 167-177. https://doi.org/10.1023/A:1014584509011

Klute, M. M. (2012). Connecting research to practice: Viewing data utilization through the lens of professional development. Early Education \& Development, 24(1), 63-67. https://doi.org/10.1080/10409289.2013.736129

Kluczniok, K. (2017). Early family risk factors and home learning environment as predictors of children's early numeracy skills through preschool. SAGE Open, 7(2), 1-13. https://doi.org/10.1177/2158244017702197

Kohm, K. E., Holmes, R. M., Romeo, L., \& Koolidge, L. (2016). The connection between shared storybook readings, children's imagination, social interactions, affect, prosocial behavior, and social play. International Journal of Play, 5(2), 128-140, https://doi.org/10.1080/21594937.2016.1203895

Landry, S. H., Anthony, J. L., Swank, P. R., \& Monseque-Bailey, P. (2009). Effectiveness of comprehensive professional development for teachers of at-risk preschoolers. Journal of Educational Psychology, 101(2), 448-465. https://doi.org/10.1037/a0013842

Leahy, R. L. (1990). The development of concepts of economic and social inequality. New Directions for Child and Adolescent Development, 46, 107-120. https://doi.org/10.1002/cd.23219904608

Leal, D. (1993). Storybooks, Information books, and informational storybooks: An explication of the ambiguous grey genre. New Advocate, 6(1), 61-70.

Lo, H. H.-M., Zhang, J., \& Choi, C.-W. (2020). Short-term psychological interventions on economically disadvantaged families: A systematic review and meta-analysis. Research on Social Work Practice, 30(3), 330-343. https://doi.org/10.1177/1049731519870273

Maier, M., Vitiello, V. E., \& Greenfield, D. B. (2012). A multilevel model of child- and classroom-level psychosocial factors that support language and literacy resilience of children in Head Start. Early Childhood Research Quarterly, 27, 104-114. https://doi.org/10.1016/j.ecresq.2011.06.002

Martucci, K. (2016). Shared storybook reading in the preschool setting and considerations for young children's theory of mind development. Journal of Early Childhood Research, 14(1), 55-68. https://doi.org/10.1177/1476718X14523750

McLoyd, V. C. (1998). Socioeconomic disadvantage and child development. American Psychologist, 53(2), 185-204. https://doi.org/10.1037/0003-066X.53.2.185

PROBLEMS

OF EDUCATION

IN THE $21^{\text {st }}$ CENTURY

Vol. 78, No. $6 \mathrm{~A}, 2020$

1093 
Chiu-Hua HUANG, Fin-Land CHENG, Ching-Yueh TENG. Teaching practices: Integrating positive thinking in picture book creation for economically disadvantaged children

PROBLEMS

OF EDUCATION

IN THE $21^{\text {st }}$ CENTURY Vol. 78, No. 6A, 2020

1094

Ministry of Health and Welfare. (2020). Statistics \& Publications: Low-income households. https://dep. mohw.gov.tw/DOS/np-2963-113.html

Parcel, T. L., \& Dufur, M. J. (2001). Capital at Home and at School: Effects on Student Achievement. Social Forces, 79(3), 881-911. https://doi.org/10.1353/sof.2001.0021

Pentimonti, J. M., Justice, L. M., Yeomans-Maldonado, G., McGinty, A. S., Slocum, L., \& O’Connell, A. (2017). Teachers' use of high- and low-support scaffolding strategies to differentiate language instruction in high-risk/economically disadvantaged settings. Journal of Early Intervention, 39(2), 125-146. https://doi.org/10.1177/1053815117700865

Penuel, W. R., Bates, L., Gallagher, L. P., Pasnik, S., Llorente, C., Townsend, E., \& VanderBorght, M. (2012). Supplementing literacy instruction with a media-rich intervention: Results of a randomized controlled trial. Early Childhood Research Quarterly, 27(1), 115-127. https://doi.org/10.1016/j.ecresq.2011.07.002

Phillips, E. C., \& Sturm, B. W. (2013). Do picture books about starting kindergarten portray the kindergarten experience in developmentally appropriate ways? Early Childhood Education Journal, 41, 465-475. https://doi.org/10.1007/s10643-012-0560-7

Reynolds, A. J., Temple, J. A., Robertson, D. L., \& Mann, E. A. (2002). Age 21 cost-benefit analysis of the title I Chicago child-parent centers. Educational Evaluation and Policy Analysis, 24(4), 267-303. https://doi.org/10.3102/01623737024004267

Shukri, M., Zin, Z., Zainol, K., Said, S., \& Rajali, A. (2019). The effectiveness of a computer-based method to support eating intervention among economically disadvantaged children in Malaysia. Health Education Journal, 78(5), 497-509. https://doi.org/10.1177/0017896918823325

Snyder, C. R. (1994). Psychology of hope: You can get there from here. Free Press.

Snyder, C. R. (2000). Handbook of hope: Theory, measures, and applications. Academic Press.

Snyder, C. R. (2005). Teaching: The lessons of hope. Journal of Social and Clinical Psychology, 24(1), 72-84. https://doi.org/10.1521/jscp.24.1.72.59169

Snyder, C. R., Cheavens, J., \& Sympson, S. C. (1997). Hope: An individual motive for social commerce. Group Dynamics: Theory, Research, and Practice, 1, 107-118. https://doi.org/10.1037/1089-2699.1.2.107

Snyder, C. R., Lehman, K. A., Kluck, B., \& Monsson, Y. (2006). Hope for rehabilitation and vice versa. Rehabilitation Psychology, 51(2), 89-112. https://doi.org/10.1037/0090-5550.51.2.89

Snyder, C. R., Lopez, S. J., Shorey, H. S., Rand, K. L., \& Feldman, D. B. (2003). Hope theory, measurements, and applications to school psychology. School Psychology Quarterly, 18(2), 122139. https://doi.org/10.1521/scpq.18.2.122.21854

Tompkins, V. (2015). Improving low-income preschoolers' theory of mind: A training study. Cognitive Development, 36, 1-19. https://doi.org/10.1016/j.cogdev.2015.07.001

Tompkins, V., Benigno, J. P., Kiger Lee, B., \& Wright, B. M. (2018). The relation between parents' mental state talk and children's social understanding: A meta-analysis. Social Development, 27(2), 223-246. https://doi.org/10.1111/sode

Vågerö, D., \& Illsley, R. (1995). Explaining health inequalities: Beyond black and barker: A discussion of some issues emerging in the decade following the black report. European Sociological Review, 11(3), 219-241. https://doi.org/10.1093/oxfordjournals.esr.a036361

Waters, L. (2011). A review of school-based positive psychology interventions. The Australian Educational and Developmental Psychologist, 28(2), 75-90. https://doi.org/10.1375/aedp.28.2.75

Received: October 22, 2020

Accepted: December 26, 2020 
Chiu-Hua HUANG, Fin-Land CHENG, Ching-Yueh TENG. Teaching practices: Integrating positive thinking in picture book creation for economically disadvantaged children

PROBLEMS

OF EDUCATION

IN THE $21^{\text {st }}$ CENTURY

Vol. 78, No. 6A, 2020

1095

Cite as: Huang, C.-H., Cheng, F.-L., \& Teng, C.-Y. (2020). Teaching practices: Integrating positive thinking in picture book creation for economically disadvantaged children. Problems of Education in the $21^{\text {st }}$ Century, 78(6A), 1081-1095. https://doi.org/10.33225/pec/20.78.1081

\begin{tabular}{|ll} 
Chiu-Hua Huang & $\begin{array}{l}\text { PhD, Assistant Professor, Department of Early Childhood Education, } \\
\text { National Pingtung University, No.4-18, Minsheng Rd., Pingtung City, } \\
\text { Pingtung County 900, Taiwan. } \\
\text { E-mail: huangchiuhua19@gmail.com } \\
\text { ORCID: https://orcid.org/0000-0001-6997-9745 }\end{array}$ \\
\hline $\begin{array}{l}\text { Fin-Land Cheng } \\
\text { (Corresponding author) }\end{array}$ & $\begin{array}{l}\text { Professor, Department of Early Childhood Education, National Pingtung } \\
\text { University of Science and Technology, 1 Shuefu Road, Neipu, Pingtung } \\
\text { E-mail: chenfl@mail.npust.edu.tw }\end{array}$ \\
\hline Ching-Yueh Teng & $\begin{array}{l}\text { Pre-school Teacher, The Affiliated Preschool of Fong-Ciou Elementary } \\
\text { School, No.77, Gaoping Ln., Xinyi Township, Nantou County 556, Taiwan. } \\
\text { E-mail: nataliedeng.nd@gmail.com }\end{array}$
\end{tabular}

